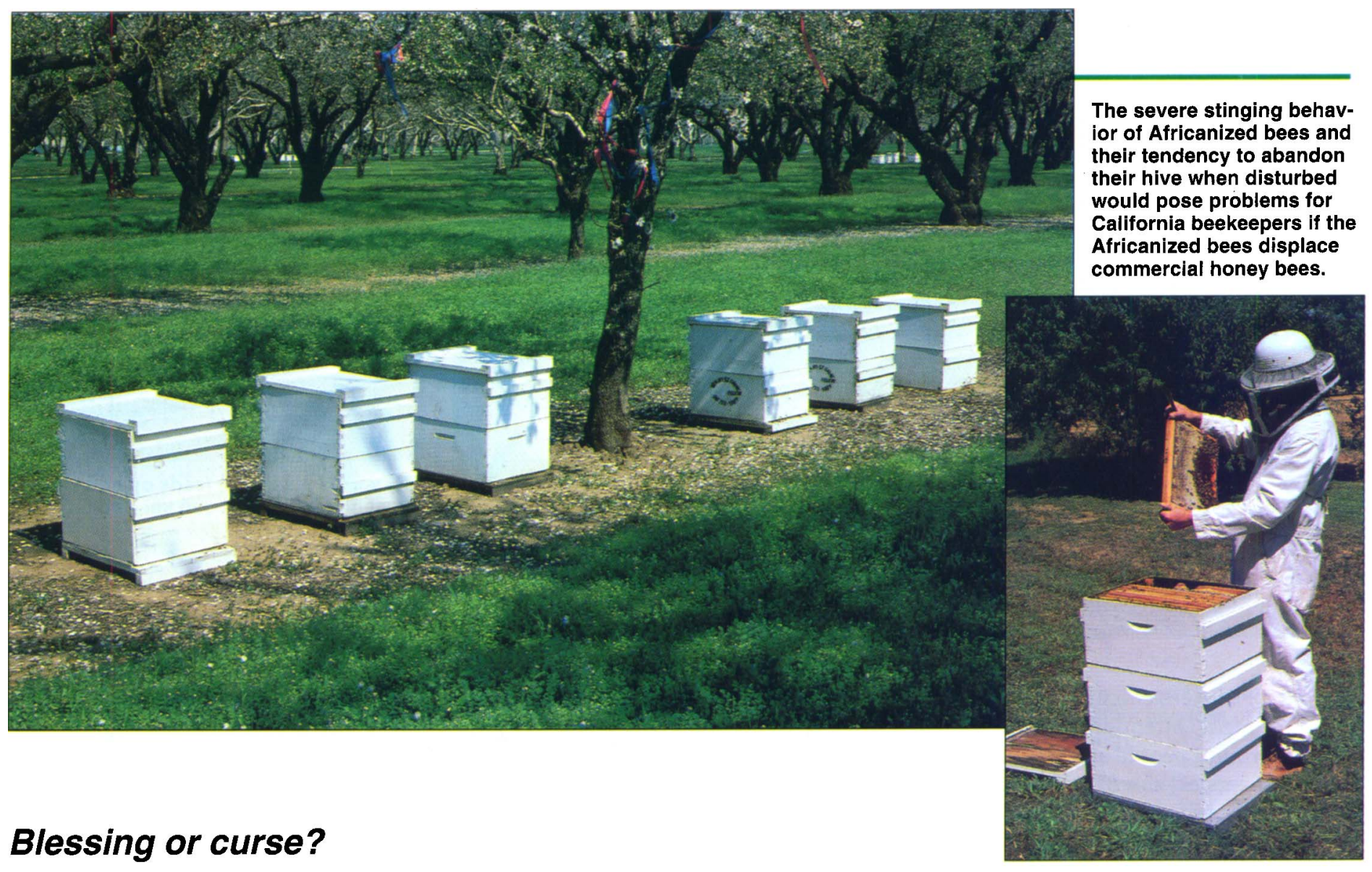

\title{
Varroa mite impacts Africanized bee spread and beekeeping
}

\author{
Robert E. Page, Jr.
}

\begin{abstract}
Africanized honey bees were first detected in California in October 1994. Since then, they have established a foothold in the Imperial Valley and have spread toward San Diego and into Palm Springs. However, their spread has been much slower than originally expected. What has slowed them? The best guess is Varroa jacobsoni, an exotic ectoparasite of honey bees recently introduced into North America. The effects of varroa on Africanized honey bees may be both a blessing and a curse; the latter is especially true if Africanized bees become resistant to varroa and commercial honey bees do not.
\end{abstract}

African honey bees (Apis mellifera scutellata) were introduced into the New World in 1956 by a prominent Brazilian geneticist. His objective was to cross African bees, known as productive honey producers in tropical environments, with honey bees of European origin (primarily Apis mellifera mellifera). European honey bees are not well suited for tropical apiculture, but are very docile (nondefensive) compared with African bees. The combination of African and European genes were to be the foundation genetic material for a planned artificial selection program to produce a tropical "super bee." However, plans went awry as the African bees and/or their hybrids known as "Africanized" honey bees (AHB) became established as a feral population in southern Brazil. During the 30 years following their introduction into Brazil, Africanized honey bees spread across South America and North America, displacing the commercial and feral European bees that had been originally introduced. Today, they are distributed throughout the southern parts of Texas, New Mexico, Arizona and California.

\section{Impact of AHB on agriculture}

The impact of AHB on California's agriculture will depend ultimately on where they are distributed throughout the state. AHB have a number of traits that make them unacceptable for use as transportable pollinators, an essential role for California's commercial bees (Page 1992). Severe stinging be- 


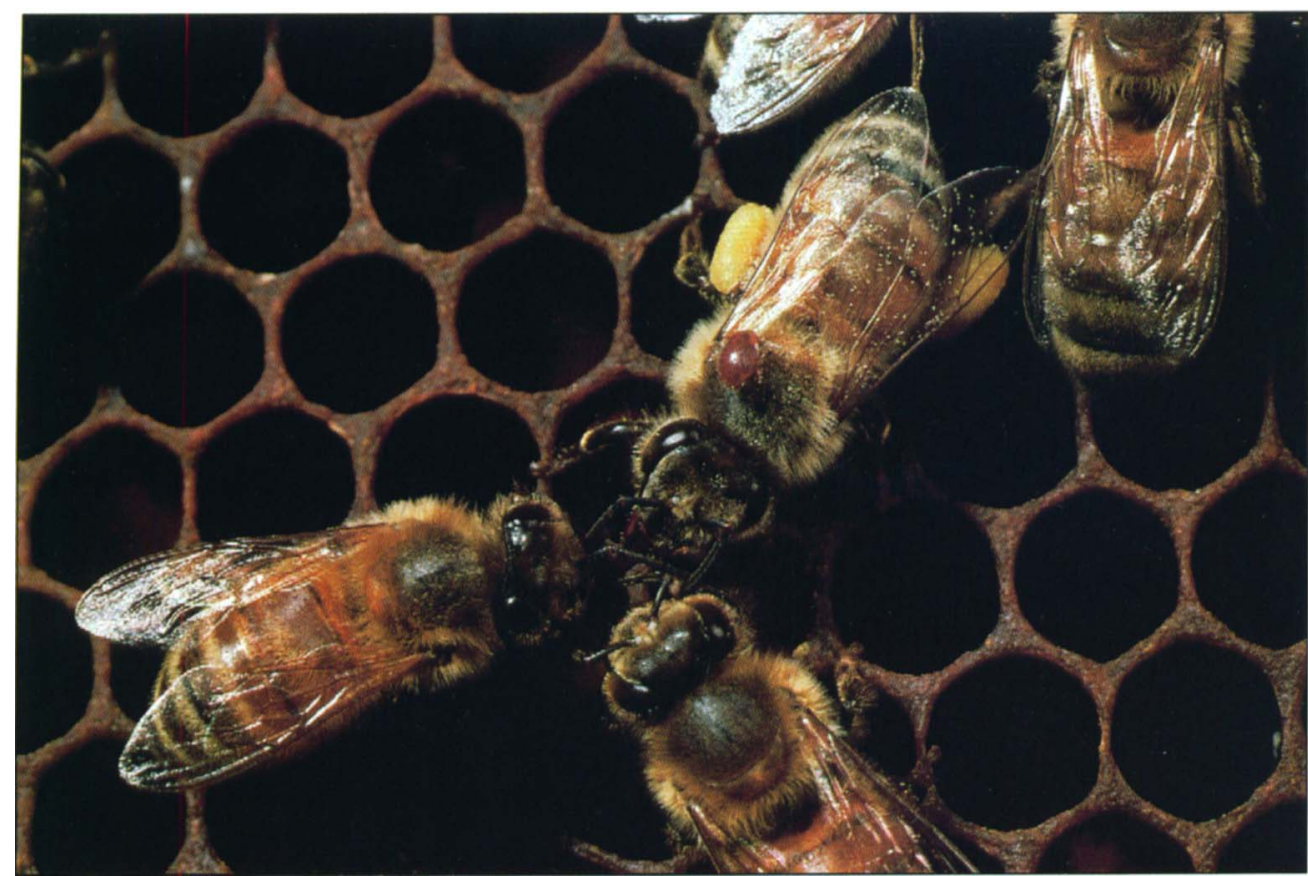

havior of AHB colonies, the focus of most media attention, precludes their use around people and livestock. In addition, colonies of $\mathrm{AHB}$ that have been disturbed by beekeepers are likely to abandon their hive (abscond) and move to a new location. This has been a serious difficulty for beekeepers in Mexico who practice migratory beekeeping with AHB. Colonies of AHB will also desert their hive at the end of a nectar flow when food resources diminish. During periods of plentiful food supply, AHB colonies invest heavily in reproduction, producing reproductive swarms that result in the division of colonies and, as a consequence, a loss of bees. This absconding and swarming behavior leads to a loss of viable colonies, and revenue, for beekeepers (GuzmánNovoa and Page 1994a).

\section{Spread of AHB in California}

Africanized bees were first detected in California near Blythe in October 1994. They were detected soon after in the Imperial Valley near El Centro.

Their spread of more than 1,000 miles from the Texas Gulf of Mexico, across northern Mexico and southern Arizona took less than 3 years, an annual rate in excess of the (200 to 300 miles observed in South and Central America. However, since their 1994 detection in California they have spread less than 100 miles, far slower than expected.
Studies conducted by Deborah Smith of the University of Kansas (Smith et al, 1989), and Glenn Hall of the University of Florida (Hall and Muralidharan 1989) demonstrated that feral honey bees distributed throughout the range of Africanized bees in North America and South America had mitochondria that were characteristic of bees of African origin. Mitochondria are intracellular organelles that replicate with each cell division and have their own DNA that is distinct from the DNA contained in the nucleus of cells. Mitochondria are contained in both the egg and sperm at the time of egg fertilization, but only the mitochondria of the egg divide and are maintained by the cells of the developing embryo. Therefore, mitochondria are inherited from the mother and are inherited through unbroken maternal lineages. The feral honey bee populations studied by Smith and Hall also had morphological and behavioral characteristics of African bees suggesting that the feral population was mostly African, rather than hybrid, in origin and had been affected little by the gene pool of the commercial and feral European bees that they had displaced.

The standard method of determining AHB developed by the United States Department of Agriculture (USDA) is based on measurements of many morphological characteristics of

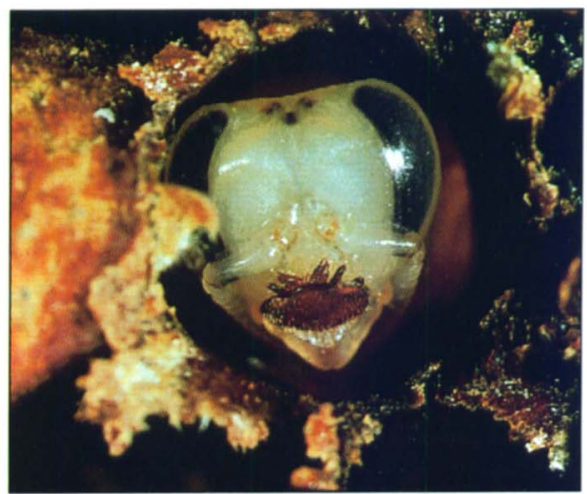

The varroa mite (red) feeds on adult and larval honey bees. It can kill a colony in as little as 6 months. honey bees (Rinderer et al. 1993). With this method, colonies that contain highly Africanized bees can be discriminated from those that are not highly Africanized. However, this method fails to classify as Africanized most colonies that are intermediate in degree of Africanization (GuzmánNovoa and Page 1994b). Therefore, a classification method using mitochondrial DNA was developed in my laboratory to assist in determining the extent of the spread of AHB in

California. This method was derived from that of Hall and Smith (1991).

The mitochondrial DNA technique is faster, easier, more reliable, and less expensive than the standard morphological identification method.

We trained personnel from the Plant Pest Diagnostics Branch of the California Department of Food and Agriculture (CDFA) to perform the DNA analyses and now routinely use them to monitor the spread of AHB. Extensive surveys conducted by my lab and in collaboration with CDFA prior to the first AHB detection (based on USDA-approved morphological methods) failed to detect any bees in California with the mitotype carried by AHB. Since the first official morphometrically detected AHB colony, increasing numbers of bees with the AHB mitotype have been detected. Surveys of Southern California conducted over the past 3 years have 
demonstrated that the feral population of Africanized honey bees continues to spread and increase in density, although at a slower rate than expected.

\section{AHB spreading slowly}

There have been several hypotheses proposed for the slowing spread of AHB throughout California, and the rest of the United States: (1) AHB have reached their ecological limits. This argument seems likely when one looks at the distribution of AHB in the United States. It appears to be limited to the hot and arid regions of the Southwest. However, AHB are distributed throughout cooler and wetter regions of Mexico, including Mexico City, and southward into temperate regions of Argentina, making this argument less plausible; (2) AHB have been interbreeding with commercial European bees and their gene pool is "diluting." There is little evidence for the genetic dilution of feral AHB by commercial bee populations. Nearly everywhere AHB have spread, the feral populations have become progressively more Africanized through time as determined by morphology, protein analyses and mitochondrial genetic markers. In the Imperial Valley, there is a growing proportion of feral bees that are African in type. These are apparently direct maternal descendants of the African queens originally imported into Brazil in 1956; and (3) A new exotic pest, Varroa jacobsoni, is controlling the spread of AHB. This is the most plausible explanation and is discussed below.

\section{Mite's effects on honey bees}

Varroa jacobsoni, also known as varroa, is an ectoparasite of honey bees. The mite feeds on adult and larval honey bees and kills colonies. Its ancestral host is the eastern honey bee, Apis cerana, on which it is not a serious problem. Varroa was first detected as a pest on the western honey bee Apis mellifera in the 1960s throughout Asia. Apis mellifera had been imported into those regions where the indigenous bee was Apis cerana. Today varroa is the most serious problem for beekeep- ers worldwide. Varroa were spread around the world through the uncontrolled transportation of honey bees and were first detected in the United States in 1987. Later that same year it was found in California. In 1991, varroa caused the first losses of California com-

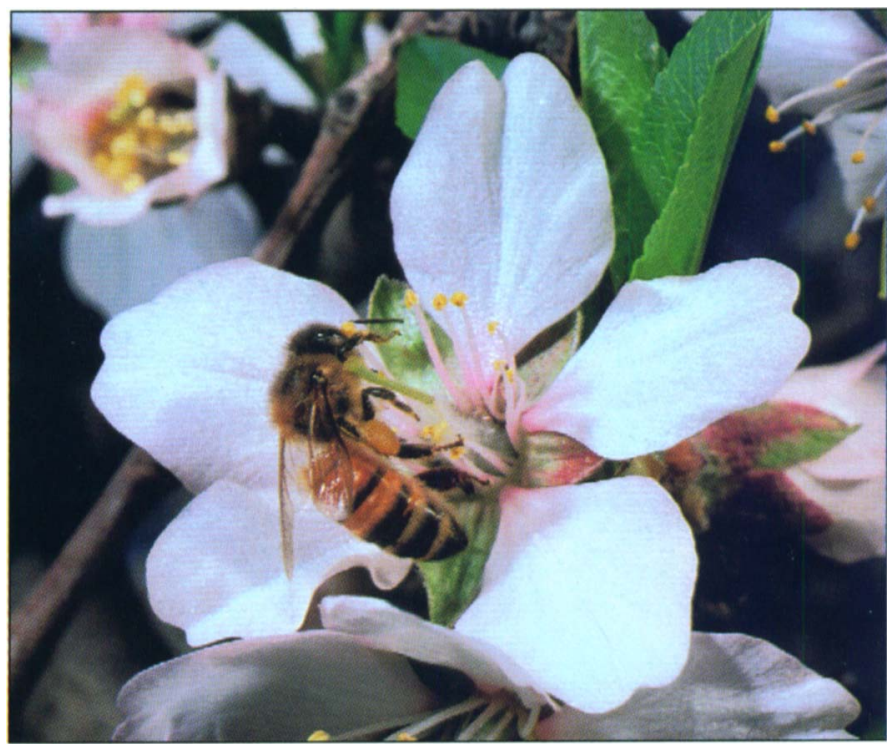
mercial colonies.

In 1992, beekeepers in the Sacramento area reported more than $50 \%$ of their colonies were lost to varroa (Kraus and Page 1995a).

Populations of varroa build up very rapidly in commercial colonies in California (Kraus and Page 1995b). We estimated that mite populations grow within colonies at a rate of about $13 \%$ per week in the summer half of the year and $10 \%$ per week in the winter half. This rate of growth results in an annual 286-fold increase.

In Central California, we found a distinct pattern of mite invasion corresponding to the seasonal patterns of nectar availability. We monitored colonies and found that when nectar was scarce or absent, there were more mites invading hives, presumably due to the robbing activities of the bees. Colonies that become weakened by varroa are unable to defend themselves from other colonies. Varroa move onto the robber bees when they enter the foreign colony and return with them to the invading colony. Over a 24-week period, we detected an average of about 200 mites invading each of our monitor colonies. With mite populations increasing $10 \%$ to $13 \%$ per week, bee colonies were overwhelmed by the parasites and soon collapsed. To avoid devastation by varroa mite, California beekeepers now treat their colonies with Apistan, a miticide containing fluvalinate, twice per year.
California's $\$ 1$ billion almond industry depends on the pollination services of honey bees to produce a crop.

In 1990, before varroa became a serious problem, we conducted a study of the feral honey bee population of California. Samples of bees were collected from 208 feral colonies distributed widely in nest sites throughout the state. We failed to find any colonies infested with varroa (Kraus and Page 1995a). In 1993, we reinspected 124 of the original nest sites and the findings were alarming. Around Sacramento - an area with intensive commercial beekeeping - only $25 \%$ of the original nest sites still had colonies of bees living in them. All surviving colonies were infested with varroa. Honey bees nest in enclosed cavities that are usually not easily accessible. However, in some cases the inside of an empty nest was exposed and could be inspected. In every case, dead varroa were found in the bottom of the nest - the smoking gun. The surviving colonies were examined again the following spring (1994). Only one remained and it was heavily infested and unlikely to survive.

Regions of California that had smaller populations of commercial hives in 1993 (as a result of less commercial beekeeping) had reduced levels of infestation of varroa and higher survival in the feral bees. It appears that varroa spread through the feral 


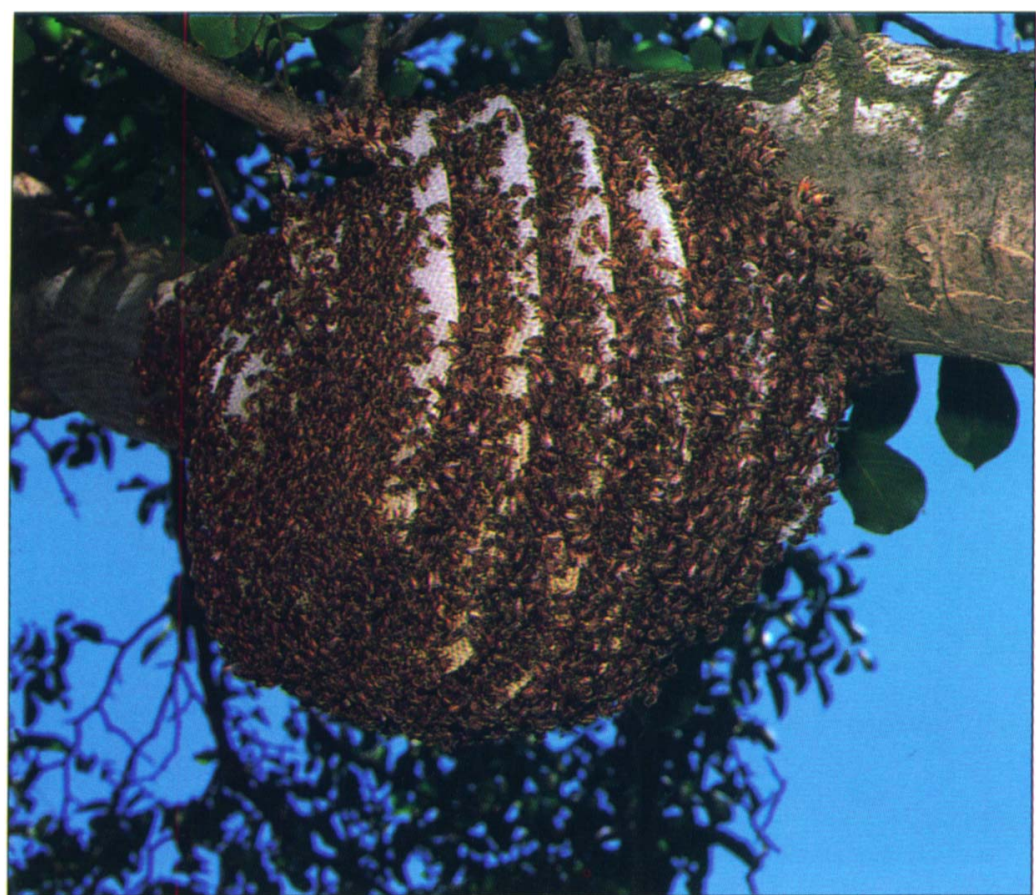

Scientists expected the population of Africanized bees to expand and displace feral bees (above), but instead feral bees have been decimated by varroa mites. The mites have killed more than $85 \%$ of the feral colonies in some areas of California.

population aided by the activities of commercial beekeeping. We used estimates of reoccupation rates and rates of survival to estimate life expectancy. Estimations of nest site reoccupation rates following the death of a feral colony and rates of survival resulted in an estimate of the life expectancy of a feral colony before and after the arrival of varroa in areas with intensive commercial beekeeping. Prior to varroa's arrival, the life expectancy was 3.5 years; after varroa arrived the life expectancy was only 6 months to a year. In 3 short years, varroa had reduced the feral population to a tiny fraction of what it had been in 1990 . As a consequence of varroa, the feral population of California is greatly reduced to about $15 \%$ of its original size in areas with extensive commercial beekeeping. Feral bees are therefore expected to have a greatly reduced effect on the gene pool of the invading AHB. Also, a smaller feral population should result in less competition for invading $\mathrm{AHB}$ for food and nest site resources. This is especially true if the AHB are relatively resistant to varroa.

\section{Resistance to varroa?}

For many years, reports have been coming from Brazil that AHB are resistant to varroa. These reports have been confounded with results demonstrating that varroa have a less severe effect on all colonies, even European, in tropical versus temperate climates (Moretto et al. 1991). Resistance, however, is plausible because of the greatly reduced effect that varroa have on their natural host, $A$. cerana, a close relative of our western honey bee. Recent evidence from Brazilian researchers suggests that, like A. cerana, Brazilian AHB have the ability to detect varroa on the bodies of adult workers and remove them (Moretto et al. 1993). This may provide a mechanism for resistance. Varroa were introduced into southern Brazil in 1972, after the spread of AHB, so the proposed resistance may have been selected in Brazil and may not be a characteristic of the spreading population of AHB. Or, AHB may be "preadapted" to be more resistant to varroa than are bees of European origins. The AHB population spreading into California did not encounter varroa until after it had invaded Mexico and Texas.

We studied some aspects of varroa resistance in Mexico shortly after varroa were first detected in colonies of AHB (Guzmán-Novoa et al. 1996).

Varroa-infested colonies were provided with immature larvae from sources of European and Africanized honey bees that were located in central Mexico. We inspected brood after they developed into pupae, sufficient time for the female mites to enter the brood cells and lay eggs. Brood cells contain- ing European honey bee pupae were twice as likely to have mites than were brood cells with AHB pupae, suggesting they were more attractive as host larvae.

In a parallel study, European and Africanized adult workers were placed together into infested colonies, then recovered two weeks later and inspected for mites. European workers were twice as likely to have varroa on them as were Africanized workers, either because they were more attractive hosts or better at grooming the mites off of their bodies. Our results suggest that AHB may be preadapted to be relatively resistant to varroa. At least two resistance mechanisms may be operating. One affects the attractiveness of honey bee larvae as hosts for female mite oviposition, the other the host attractiveness or grooming abilities (as shown by Morreto et al. 1993) of adults. However, varroa are still causing serious damage to colonies of $\mathrm{AHB}$ in Mexico.

Reports from Brazil claim that varroa is not a serious problem there, possibly the result of strong selection for 28 years on a large, feral AHB population. In North America, it is likely that varroa are having two effects on the spread of AHB. They have reduced potential competition from feral and commercial European bees. This could be a "curse" for California's agriculture because reduced competition could result in an increased rate of spread and higher colony densities of Africanized bees. However, varroa are also reducing the rate of growth and life expectancy of feral AHB colonies, resulting in reduced population densities and slower spread, a "blessing." This effect may be only temporary if AHB can evolve greater resistance to varroa. It is unlikely that European bees will evolve resistance because commercial beekeepers must treat their colonies with miticides to stay in business. Varroa eliminate feral European colonies that are then replaced either with AHB or with European colonies derived from nonresistant commercial colonies. In the end, AHB will spread to their ecological limits, wherever they may be. 
R.E. Page, Jr., is Professor of Entomology, Department of Entomology, UC Davis.

The author thanks the many people who have been involved in the research summarized above, especially Kim Fondrk, Bernhard Kraus, Ernesto Guzmán-Novoa, Dave Nielsen, Scott Kinnee, Paul Ebert, David Chance and Mike Crosland. This research has been funded primarily by contracts from the California Department of Food and Agriculture, the Almond Board of California, and the California State Beekeepers Association.

\section{References}

Guzmán-Novoa E., Page RE. 1994a. The mpact of africanized bees on Mexican beekeeping. Am Bee J 134: 101-6.

Guzmán-Novoa E, Page RE. 1994b. Morphometric techniques do not detect intermediate and low levels of africanization in honey bee (Apis mellifera L.) colonies. Ann Entomol Soc Am 87: 507-15

Guzmán-Novoa E, Sanchez A, Page RE, Garcia T. 1996. Susceptibility of European and Africanized honeybees (Apis mellifera L.) and their hybrids to Varroa jacobsoni Oud. Apidologie 27: 93-103

Hall HG, Muralidharan K. 1989. Evidence from mitochondrial DNA that African honey bees spread as continuous maternal lineages. Nature 339: 211-13.

Hall HG, Smith DR. 1991. Distinguishing African and European honeybee matrilines using amplified mitochondrial DNA. Proc Nat Acad Sci USA 88: 4548-52.

Kraus B, Page RE. 1995a. Effect of Varroa jacobsoni (Mesostigmata: Varroadae) on feral Apis mellifera (Hymenoptera: Apidae) in California. Environ Entomol 24: 1473-80.

Kraus B, Page RE. 1995b. Population growth of Varroa jacobsoni Oud in Mediterranean climates of California. Apidologie 26 149-57.

Moretto G, Gonçalves LS, De Jong D, Bichuette MZ. 1991. The effects of climate and bee race on Varroa jacobsoni Oud infes. tations in Brazil. Apidologie 22: 197-203

Moretto G, Gonçalves LS, De Jong D. 1993. Heritability of Africanized and European honeybee defensive behavior against the mite Varroa jacobsoni. Braz J Genet 16 $71-7$

Page RE. 1992. How Africanized bees will affect California agriculturé. Cal Ag 46:18-19.

Rinderer TE, Buco SM, Rubink WL, Daly HV , Stelzer JA, Riggio RM, Baptista FC 1993. Morphometric identification of Africanized and European honey bees using large reference populations. Apidologie 24: 569-85.

Smith DR, Taylor OR, Brown WM. 1989 Neotropical Africanized honey bees have African mitochondrial DNA. Nature 339: 213-15.

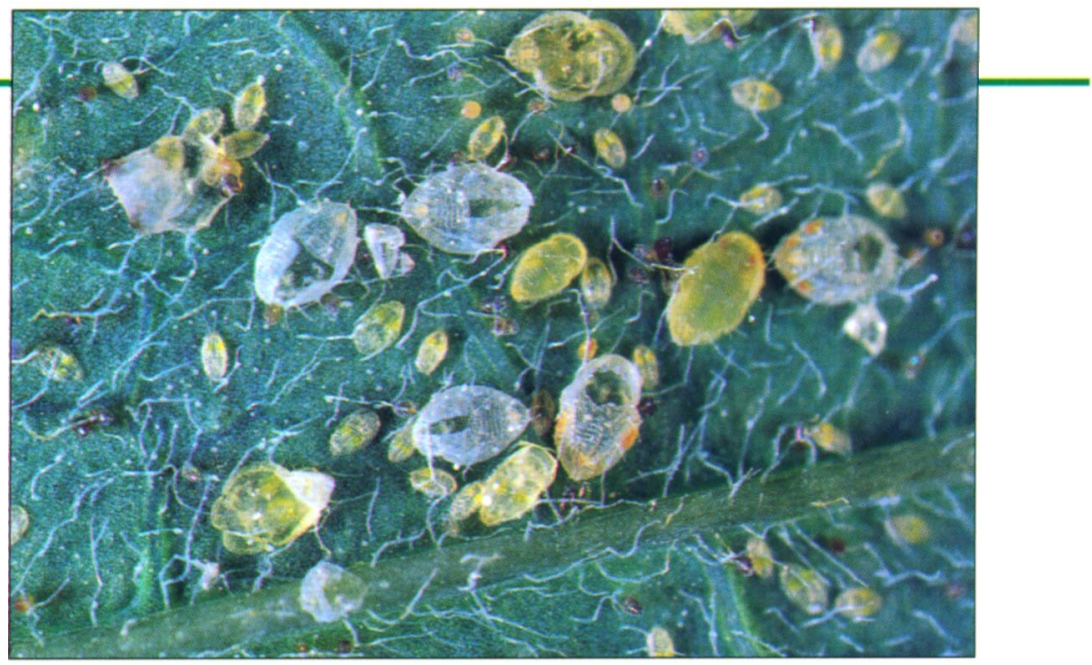

Exotic species invade the state continually. Two which have exacted high tolls are sweetpotato whitefly and silverleaf whitefly; nymphal stages of both are shown above.

\title{
Invasion biology: Rethinking our response to alien species
}

\author{
Robert C. Venette $\square \quad$ James R. Carey
}

Invasion biology is the study of the reproduction, dispersal and ecological impact of organisms that occur outside of their native range, including exotic pests and biological control agents. Alien species cost California agriculture billions of dollars annually in control measures and crop damage. Societal trends toward increased travel and import of plant and animal products suggest that exotic species will continue to enter California. Understanding the principles of the invasion process will help to predict which species will invade, where invaders will become established, and the effects of invasions on agricultural, urban and natural environments. Improved understanding of the invasion process should contribute to public policies designed to prevent or contain invasions, especially of potential pests that are not yet in the state and whose biology is poorly described.
More species are invading California today than at any other time in the state's history. Currently, more than 2,300 exotic species reside in the state, including 1,025 plants, 42 freshwater fish, 11 mammals, 9 birds and 208 invertebrates. While most introduced organisms fail to become established, those that do can become serious pests in agriculture, urban areas and natural landscapes. Alien species cost California agriculture billions of dollars annually in control measures and crop damage. In addition to their economic impact, some exotic organisms may threaten human health, displace native species or degrade environmental aesthetics. Consequently, many growers, conservationists, researchers and regulatory agencies share a similar commitment to mitigating and preventing unwanted invasions.

Recent efforts sponsored by UC in cooperation with the California Department of Food and Agriculture (CDFA) have inspired novel concepts about the processes that underlie both successful and unsuccessful invasions. 